\title{
Nurse led secondary prevention clinics improved health and decreased hospital admissions in patients with coronary heart disease
}

\author{
Campbell NC, Thain J, Deans HG, et al. Secondary prevention clinics for coronary heart disease: randomised trial of effect on \\ health. BMJ 1998 May 9;316:1434-7.
}

\section{Question}

Can nurse led secondary prevention clinics improve health and decrease symptoms for patients with coronary heart disease (CHD)?

\section{Design}

Randomised controlled trial with 12 months follow up.

\section{Setting}

19 general practice clinics in north east Scotland.

\section{Patients}

1343 patients with CHD from randomly selected general practice clinics. At baseline, $47 \%$ had chest pain in the previous week. Patients were excluded if they had a terminal illness or dementia, or were housebound. Follow up was $87 \%$ (mean age 66 y, $58 \%$ men).

\section{Intervention}

Patients in the intervention group $(n=673)$ were invited to attend nurse led secondary prevention clinics during the first 3 months for assessment of their symptoms, treatment, blood pressure, lipid management, and lifestyle factors; promotion of aspirin use; behavioural counselling; and regular follow up visits for 1 year. Patients in the control group $(n=670)$ received routine care.

\section{Main outcome measures}

Functional status, wellbeing, and general health perception (SF-36 Health Survey Questionnaire); presence, frequency, and course of chest pain; anxiety and depression (Hospital Anxiety and Depression Scale); and hospital admissions and general practitioners visits.

\section{Main results}

Analysis was by intention to treat. Patients in the intervention group had improved functional status and general health perceptions $(\mathrm{p}<0.05$, adjusted for age and baseline performance). After adjustment for age, sex, general practice, and baseline performance, fewer patients in the intervention group had worsening of chest pain $(\mathrm{p}=0.025)$ and required hospital admission $(\mathrm{p}=0.003)$ (table). No differences existed for presence or frequency of chest pain, change in anxiety and depression between baseline and 1 year, length of hospital stay, and number of general practitioner visits.

\section{Conclusions}

In patients with coronary heart disease, nurse led secondary prevention clinics that offered regular follow up visits improved functioning and health perceptions and reduced hospital admissions but did not affect anxiety, depression, length of hospital stay, or number of general practitioner visits.

Clinic v usual care for secondary prevention in patients with coronary heart disease

\begin{tabular}{lllll}
\hline Outcomes at 12 months & $\begin{array}{l}\text { Clinic } \\
\text { care }\end{array}$ & $\begin{array}{l}\text { Usual } \\
\text { Care }\end{array}$ & $\begin{array}{l}\text { Adjusted odds ratio } \\
\text { (95\% CI) }\end{array}$ & NNT (CI) \\
\hline $\begin{array}{l}\text { Worsening of chest } \\
\text { pain }\end{array}$ & $7 \%$ & $11 \%$ & $0.59(0.37$ to 0.94$)$ & $24(16$ to 170$)$ \\
$\begin{array}{l}\text { Hospital admissions } \\
\text { Pos }\end{array}$ & $20 \%$ & $28 \%$ & $0.64(0.48$ to 0.86$)$ & $13(9$ to 35$)$ \\
\hline
\end{tabular}

*Abbreviations defined in glossary; NNT and CI calculated from data in article.

Source of funding: Chief Scientist Office at the Scottish Office.

For correspondence: Dr N C Campbell, Department of General Practice and Primary Care, Foresterhill Health Centre, Aberdeen AB25 2AY, UK. Fax +44 (0)1224 840683.

\section{Commentary}

Research shows that patients with CHD who have had a myocardial infarction or coronary artery bypass grafting and participate in rehabilitation programmes have shorter hospital stays, reduced recurrent disease, and decreased cardiovascular mortality. ${ }^{1}$ Despite this, only a small proportion of people with $\mathrm{CHD}$ are in rehabilitation. ${ }^{2}$ In this study, $71 \%$ of eligible patients with CHD agreed to participate, and $82 \%$ of the intervention group attended at least 1 nurse run clinic. Although the intervention in this study was less intensive than standard rehabilitation programmes, this approach had an impact on health and hospital admission rates. Well validated self report measures were used. An analysis of outcomes by intensity of intervention would be instructive, however.

Nurse run programmes are effective and may be a cost effective approach to secondary prevention. Nurse specialists can facilitate many areas in the implementation of optimal care. For dyslipidaemia, strong evidence supports aggressive cholesterol management for the reduction of cardiac events in patients with $\mathrm{CHD},{ }^{3}$ yet most patients are not being treated according to national guidelines. ${ }^{3}$ Nurse specialist anticoagulant services are as effective in maintaining therapeutic control as consultant services, and better at documenting relevant details and improving patient knowledge. ${ }^{4}$ Nurse managed clinics for outpatients with heart failure decrease lengths of hospital stay and the number of readmissions. ${ }^{5}$ This collective evidence should encourage others to take a step further and evaluate the cost effectiveness of nurse run secondary prevention.

A Kirsten Woodend, RN, MSc Nurse Specialist, Research University of Ottawa Heart Institute Ottawa, Canada

1 Pashkow FJ. Semin Thorac Cardiovasc Surg 1995;7:240-7.

2 Thomas RJ, Miller NH, Lamendola C, et al. J Cardiopulm Rehabil 1996;16:402-12

3 Taylor FC, Gaminara E, Cohen H, et al. Clin Lab Haematol 1997;19:267-72.

4 Cofer LA. Heart Lung 1997;26:337-44.

5 Lasater M. Home Healthcare Nurse 1996;14: 351-6. 